Cipango Cahiers d'études japonaises

$17 \mid 2010$

La péninsule retrouvée

\title{
Gérard MARTZEL, Les Grandes Lecture d'été - Un pas vers le théâtre Nō
}

\section{Pascal Griolet}

\section{(2) OpenEdition}

\section{Journals}

\section{Édition électronique}

URL : https://journals.openedition.org/cipango/1143

DOI : $10.4000 /$ cipango. 1143

ISSN : 2260-7706

\section{Éditeur}

INALCO

Édition imprimée

Date de publication : 30 juin 2010

Pagination : 279-281

ISBN : 978-2-85831-195-8

ISSN : $1164-5857$

\section{Référence électronique}

Pascal Griolet, "Gérard marTzeL, Les Grandes Lecture d'été - Un pas vers le théâtre Nō », Cipango [En ligne], 17 | 2010, mis en ligne le 16 novembre 2012, consulté le 30 juin 2021. URL : http:// journals.openedition.org/cipango/1143; DOI : https://doi.org/10.4000/cipango.1143

Ce document a été généré automatiquement le 30 juin 2021.

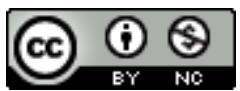

Cipango est mis à disposition selon les termes de la Licence Creative Commons Attribution - Pas d'Utilisation Commerciale 4.0 International. 


\title{
Gérard MARTZEL, Les Grandes Lecture d'été - Un pas vers le théâtre Nō
}

\author{
Pascal Griolet
}

\section{RÉFÉRENCE}

Gérard MARTZEL, Les Grandes Lecture d'été - Un pas vers le théâtre Nō, Les Indes savantes, 2008, 116 pages. ISBN 978-2-84654-194-7.

1 Un petit texte au dos de l'ouvrage en donne la présentation qui suit:

Pendant plusieurs décennies, l'auteur a pratiqué le théâtre Nō, une face fondamentale de la culture japonaise, qui a été sa "clé " vers le Japon. L'ouvrage raconte les répétitions de pièces de théâtre Nō à Kyōto, sous la férule impitoyable et tendre à la fois d'un des meilleurs professeurs du pays, "Madame». Les coulisses de cet art sont ainsi ouvertes avec les dimensions humaine et spirituelle qui l'imprègnent, qui le relient aux plus anciennes croyances du pays. L'histoire entremêlée et parallèle du vieux jardin où se déroulent ces répétitions, l'escapade de la troupe dans la montagne, auprès de sources millénaires, enrichissent encore cette approche de la civilisation japonaise.

2 Ce texte qui résume bien l'ouvrage est dû à l'éditeur car ces répétitions annuelles ne se déroulent pas à Kyōto, mais bien loin d'elle, dans le Nord-Est de l'archipel. Mais cela, au fond, n'a guère d'importance pour le propos.

Observons par ailleurs que la couverture présente un jardin dont la photographie, si on la regarde bien, laisse voir en filigrane quelques lignes d'un livret de Nō dont les signes sont indicés en noir et en rouge pour le chant et pour les gestes. Ainsi le signe " Japon » ne se révèle que si on regarde attentivement la couverture. Sans aucun doute volontairement, les signes emblématiques du Japon sont ainsi gommés ou estompés, invisibles de loin. Il faut donc ouvrir le livre et tourner plusieurs pages pour découvrir un sous-titre «Un pas vers le théâtre Nō». Il ne s'agit donc pas un ouvrage de vulgarisation mais d'une initiation. Ce caractère quelque peu ésotérique est en parfait accord avec la discipline de ce théâtre. 


\section{du théâtre Nō avec la profondeur d'un connaisseur, professeur émérite à l'Institut} National des Langues et Civilisations Orientales.

Ce qui rend cet ouvrage très original au sein de ce qui se publie sur le Japon, c'est qu'après quelques concessions dans la préface, l'auteur a fait le choix de n'employer aucun mot japonais. Il s'est démarqué de la facilité de donner le mot japonais avec sa traduction entre guillemets à côté ou des notes en bas de page, procédés qui, en un sens, polluent tant d'ouvrages sur le Japon. Ceux qui connaissent un peu ce pays devineront donc, s'ils le souhaitent, le mot japonais qui fait par exemple écho au mot "Madame », cette femme qui donnait chez elle des cours tous les étés pour pratiquer le chant et la danse.

6 L'auteur maîtrise un français de très haute qualité, presque précieux parfois, et il connaît si bien le Japon que ses traductions sont souvent magnifiques, admirables. Décrire ainsi en profondeur la pratique du Nō grâce à la finesse de la langue française, c'est une belle leçon. L'auteur prend son lecteur par la main pour l'introduire après un dédale de rues et un jardin dans la demeure de ce maître. Le jardin joue un grand rôle. C'est aussi un ouvrage sur la nature. Comme c'est généralement le cas au Japon, le jardin est conçu pour être vu depuis l'intérieur de la maison. On découvrira au passage qu'un jardin peut être masculin ou féminin!

7 Ce récit à la première personne synthétise une expérience de trente années. C'est sous cette forme que l'auteur nous guide au sein des événements même les plus triviaux. On pénètre peu à peu dans la pratique concrète du Nō : le chant, la danse, le vêtement, le maniement de l'éventail, les livrets.

Trente années sont ainsi passées en revue avec tous les aspects du déroulement de ces cours d'été, comme les buveries après les cours et chansons populaires qui les accompagnent. Les profondeurs de ce pays sont aussi évoquées par un bain chaud près d'une cascade dans la nuit, alors qu'une "tête de démon " passe comme un oiseau de nuit à l'occasion d'une excursion dans le fin fond d'une montagne dans une auberge où l'électricité n'est pas encore parvenue. Cette "tête de démon» serait, selon l'aubergiste, la «Dame de la montagne ». Même l'accent particulier de la langue des habitants du Nord-Est est délicatement évoqué.

9 Quelques photographies au milieu de l'ouvrage donnent un visage à l'extraordinaire dame chez qui se tiennent ces cours.

L'emploi du français crée aussi une distance qui fait que le lecteur sait qu'il ne connaît pas ce dont il s'agit, qu'il ne sait pas ce qu'est au juste ce monde. C'est peut-être une stratégie motivée par l'exigence d'obscurité qu'exige le Nō. Il y a une distance infinie qui ne peut-être saisie seulement par l'intellect.

11 L'ouvrage de vulgarisation donne trop souvent l'illusion de savoir ou d'avoir compris.

12 L'auteur nous fait partager non pas un regard extérieur sur le Japon, un regard « orientaliste» pourrait-on dire, mais sa communion avec les personnes qui y vivent. C'est donc du dedans que les choses sont décrites en estompant tout ce qui rendrait le Japon extérieur, comme les notes, les termes japonais ou les explications diverses, pour aller à chaque fois à l'essentiel. C'est là un précieux témoignage pour ceux qui s'intéressent à ce pays comme ceux qui s'intéressent au théâtre, au chant et à la danse, sans oublier ce que nous désignons souvent sous ce terme si mal adapté au Japon : les religions.

Cipango, $17 \mid 2010$ 